\title{
Petaloid Male-sterile Plants from Carrot Cell Cultures
}

\author{
Jolene Wright ${ }^{1}$, Ann Reilley ${ }^{2}$, Jean Labriola ${ }^{3}$, Stephanie Kut ${ }^{4}$, and \\ Thomas Orton ${ }^{5}$ \\ DNA Plant Technology Corporation, 6701 San Pablo Avenue, Oakland, \\ CA 94608
}

Additional index words. Daucus carota, carrot, cell culture, cytoplasmic male sterility, somaclonal variation

\begin{abstract}
An experiment was conducted to determine the types, extent, and heritability of new phenotypic variants recovered from carrot cell cultures initiated from mature taproot explants of the male-fertile carrot (Daucus carota L.) 'Slendero'. Embryogenic callus was transferred to plant-growth-regulator-free medium 66 days after culture initiation, and regenerated plantlets were harvested and eventually planted in a field. The tap roots of mature regenerated plants were vernalized at $5 \mathrm{C}$ for 9 weeks and replanted. Of 31 flowering regenerants, 25 exhibited some form of petaloid male sterility; the remaining six regenerants were male fertile. All plants from the same original explant were either all sterile or all fertile. Three generations of sterile regenerant $x$ petaloid cytoplasmic male sterility (CMS) maintainer (M) progeny tests showed that the new CMS behaved in a similar manner to that previously reported. Comparison of mitochondrial DNA restriction patterns of sterile and fertile regenerants with those of 'Slendero', petaloid CMS, petaloid M, and brown anther CMS lines resulted in the following conclusions: 1) the sterile regenerants exhibited patterns identical to the known petaloid CMS and 2) the fertile regenerants were different from the original 'Slendero' and the sterile regenerants and nearly identical to a known petaloid CMS M line. The high frequency of CMS among regenerants from 'Slendero' carrot cell cultures may provide an efficient method to develop sterile $M$ tandem lines and corresponding new hybrid varieties.
\end{abstract}

Cytoplasmic male sterility (CMS) is a trait used for the efficient cost-effective production of hybrid seed in many annual and biennial crop species. In most cases, CMS is governed by an interaction of genetic factors in cytoplasmic and nuclear genomes. Specifically, nuclear genes known as restorers interact with cytoplasmic genomes carrying the CMS determinant to result in the development of normal-functioning stamens and viable pollen. Restorer genes may function by either complementation of the cytoplasmic mutation or, more likely, by modulating the production of peptides responsible for or associated with

Received for publication 22 May 1995. Accepted for publication 7 Nov. 1995. The cost of publishing this paper was defrayed in part by the payment of page charges. Under postal regulations, this paper therefore must be hereby marked advertisement solely to indicate this fact.

${ }^{1}$ Former Research Associate. Current address: Spreckels Sugar Co., P.O. Box 7428, Spreckels, CA 93962.

${ }^{2}$ Former Research Associate. Current address: Dept. of Plant Pathology, Colorado State Univ., Fort Collins, CO 89056.

${ }^{3}$ Former Research Scientist. Current address: Dept of Biology, Ursinus College, Collegeville, PA 19426.

${ }^{4}$ Former Research Scientist. Current address: BristolMyers Squibb, Pharmaceutical Research Institute, P.O. Box 4000, Princeton, NJ 08543-4000.

${ }^{5}$ Former Senior Director. To whom reprint requests should be addressed. Current address: Cook College, Rutgers Univ., New Brunswick, NJ 08903. abnormal stamen and pollen development (Levings and Brown, 1989; Lonsdale et al., 1988). Fertility restoration is an important feature of hybrid seed production strategies based on CMS because it allows for sterility and fertility in the presence of responsible cytoplasmic genetic factors.

Two distinct CMS forms have been discovered in carrot, both of which are used for hybrid seed production. The petaloid form was derived from a wild carrot population and is a homeotic mutation resulting in the conversion of stamens to petal- or leaf-like structures (Peterson and Simon, 1986). The brown anther form was selected from the commercial cultivar Tendersweet and is characterized by anther abortion before pollen maturation. Nuclear restoration of brown anther CMS is complicated, involving the interaction of two to three dominant maintainers and one epistatic dominant restorer (Hansche and Gabelman, 1963; Thompson, 1962).

The development of new hybrid carrots by traditional breeding is extremely tedious and time consuming because of long generation times, difficulty in affecting crosses, and the genetic complexity of sterility maintenance. Therefore, alternative methods have been explored, most notably protoplast-mediated CMS conversion (Reynolds, 1986; Tanno- Suenaga et al., 1988). In our study, we report on the high-frequency recovery of petaloid CMS plants from cell cultures derived from a fertile, open-pollinated carrot cultivar and a genetic and molecular characterization of regenerants.
Carrot growing and cell culture protocol. Seeds from the open-pollinated 'Slendero' were sown on 15 July 1987 in an open field located in Watsonville, Calif. A planting configuration of six rows on 1.22-m-wide raised beds was used at 800,000 plants/ha. Cultural practices used to produce carrot tap roots were typical of those used in California.

On 12 Oct. 1987, 20 tap roots were selected at random from a population preselected for commercial quality; they were peeled and surface-disinfested for 20 min under agitation in $1 \%$ sodium hypochlorite with one drop Tween-20/100 ml. Roots then were cut into 1 $\mathrm{cm}$ sections and placed onto agar-solidified MS (Murashige and Skoog, 1962) medium supplemented with $0.09 \mathrm{M}$ sucrose, $4.5 \mu \mathrm{M} 2,4-$ dichlorophenoxyacetic acid (2,4-D), and 0.9 $\mu \mathrm{M}$ kinetin. Cultures from half of the original explants were maintained at $20 \mathrm{C}$ under a $16-\mathrm{h}$ photoperiod [ 30 to $50 \mu \mathrm{mol} \cdot \mathrm{m}^{-2} \cdot \mathrm{s}^{-1} ;$ cool-white fluorescent lamps (L1 to L10)], while the other half were maintained in continuous darkness (D1 to D10).

At 66 days post-explant (PE), embryogenic callus tissues were excised from the surface of the original tap-root explants and were transferred to MS medium devoid of plant growth regulators to stimulate the growth and continued development of somatic embryos. Developing plantlets were removed from culture and planted into sterilized potting soil (Supersoil; Orchard Supply, San Jose, Calif.) in $45-\mathrm{ml}$ cell plastic liners and were grown under a 16-h photoperiod (20 to 30 $\mu \mathrm{mol} \cdot \mathrm{m}^{-2} \cdot \mathrm{s}^{-1}$; cool-white fluorescent lamps) and high humidity for $115,142,182,224$, and 273 days PE. A total of 183 plantlets were regenerated successfully, of which 96 survived to vegetative maturity.

Surviving regenerants were planted into sterilized potting soil in individual 7.6-liter pots and were maintained outdoors at the DNA Plant Technology Corp. (DNAP) (Western R\&D Station, Watsonville, Calif.). On 20 Mar. 1989 , tap roots from surviving regenerants were removed from the soil, foliage was excised $1 \mathrm{~cm}$ above the apical meristem, and the basal 2 to $3 \mathrm{~cm}$ of the tap root removed. Roots prepared in this manner were dipped in $1 \%(\mathrm{w} /$ v) benomyl and were stored in moist sawdust at 5C in darkness for vernalization. On 22 May 1989 , vernalized roots were replanted into the open field at DNAP. During Summer 1989, 31 plants from among the surviving regenerants flowered. Certain male-sterile regenerants were pollinated with petaloid maintainer tester lines (4367M or 3640M, provided by Philip Simon, U.S. Dept. of Agriculture, Agricultural Research Station, Dept. of Horticulture, Univ. of Wisconsin, Madison), with a known strong restorer of petaloid CMS ('Nangro'), or a known weak restorer of petaloid CMS ('Slendero'). Progeny of crosses were examined during Summer 1990 for flowering behavior. Sterile X maintainer and restorer crosses were repeated in 1990 and 1991, and corresponding progeny were observed in 1991 and 1992 to ascertain CMS stability. 
Mitochondrial DNA restriction analyses. Each mtDNA sample was isolated from 5 to 15 $\mathrm{g}$ of fresh, young, leaf material. The isolation was essentially according to the procedures of Wilson and Chourey (1984) and Kemble (1987), with some modifications. Leaves were ground three times in a chilled mortar and pestle in a volume of ice-cold extraction buffer equal to twice the weight of leaf material for the first grinding, followed by an equal volume of extraction buffer for the second and third grindings.

Extraction buffer consisted of $0.35 \mathrm{M}$ sorbitol, $50 \mathrm{~mm}$ tris- $\mathrm{HCl}, \mathrm{pH} 8.0,5$ mм EDTA, $0.1 \%(\mathrm{w} / \mathrm{v})$ bovine serum albumin, $1 \mathrm{~mm}$ spermidine, $0.1 \%$ (w/v) PVP-40, and $30 \mathrm{~mm} 2-$ mercaptoethanol. Cellular debris and intact nuclei were removed by a 10-min centrifugation at $120 \times g$. Chloroplasts were removed by two 10 -min centrifugations at $1075 \times \mathrm{g}$, followed by one 10 -min centrifugation at $300 \times g$. Mitochondria were pelleted by a 10-min centrifugation at $17,000 \times g$. All centrifugations were conducted at $4 \mathrm{C}$.

After DNaseI treatment, the mitochondria were lysed in 1 to $2 \mathrm{ml}$ of lysis buffer [ $50 \mathrm{~mm}$ tris- $\mathrm{HCl}, \mathrm{pH} 8.0,50 \mathrm{~mm}$ EDTA, $2 \%$ (w/v) sarkosyl, and $0.012 \%(\mathrm{w} / \mathrm{v})$ proteinase $\mathrm{K}$ ] for $50 \mathrm{~min}$ at $37 \mathrm{C}$ followed by $10 \mathrm{~min}$ at $60 \mathrm{C}$ with occasional swirling. The lysate was brought up to $0.2 \mathrm{M} \mathrm{NH} 4$-acetate and was subjected to two phenol-choloroform extractions followed by a single chloroform extraction. mtDNA was precipitated with two volumes of $95 \%$ ethanol overnight. DNA pellets were resuspended in $100 \mu \mathrm{l}(10 \mathrm{~mm}$ tris- $\mathrm{HCl}, 1.0 \mathrm{~mm}$ $\mathrm{T}_{10} \mathrm{E}_{1}$ EDTA, $\mathrm{pH}$ 8.0) and reprecipitated. The second mtDNA pellet was resuspended in 5 to $15 \mu \mathrm{T}_{10} \mathrm{E}_{1}$, depending on the starting amount of leaf material (5 to $15 \mathrm{~g}$ ).

Digests of each sample were performed in a $10-\mu 1$ volume. The amount of mtDNA required for the restriction digest fragments to be visible on an agarose gel was determined by a trial digest and ranged from 1 to $5 \mu \mathrm{l}$. A total of 80 units of EcoRI, BamHI, or BglII; 70 units of HindIII; 45 units of EcoRV; 18 units of NotI; or 12 units of PvuII or HaeIII in $1 \mu \mathrm{l}$ volume were added to each digest. Also added to each digest were $1 \mu \mathrm{l}$ of $10 \times$ reaction buffer (Promega Scientific), spermidine to $4 \mathrm{~mm}$, and $62.5 \mathrm{ng}$ of RNaseA. The final volume of digests was adjusted to $10 \mu \mathrm{l}$ with sterile deionized water. All digestions were conducted at $37 \mathrm{C}$ for $6 \mathrm{~h}$.

Restriction enzyme digest fragments were resolved on 1\% (EcoRI, BamHI, HindIII, and EcoRV), 0.8\% (PvuII, BglII, and NotI), or $1.5 \%$ (HaeIII) agarose gels ( $28 \mathrm{~cm}$ long). Electrophoresis was in TBE buffer ( $89 \mathrm{~mm}$ trisborate, $89 \mathrm{~mm}$ boric acid, and $2 \mathrm{~mm}$ EDTA) at $50 \mathrm{~V}$ for 16 to $18 \mathrm{~h}$ for all enzymes, except HaeIII, which was electrophoresed at $110 \mathrm{~V}$ for $6.5 \mathrm{~h}$.

\section{Results}

More than 100 regenerants were recovered successfully, but most either perished or did not flower. Of the 31 regenerated plants that flowered, 25 exhibited some form and extent

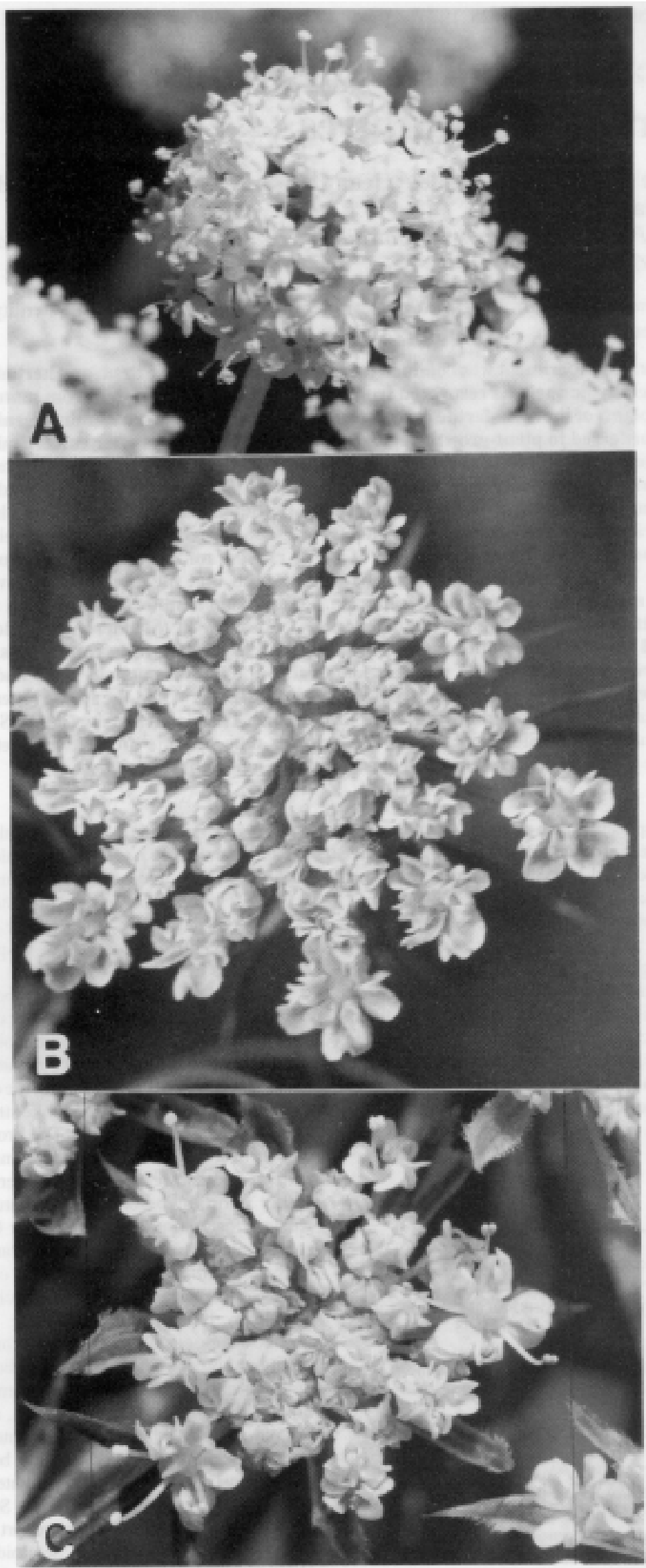

Fig. 1. Carrot floral morphology of (A) a normal male-fertile umbel, (B) a showy petaloid male-sterile umbel from a plant derived from a regenerant, and $(\mathbf{C})$ a partially fertile umbel from a plant derived from a regenerant. 
of petaloid-like male sterility (Fig. 1). Floral morphology of male-sterile regenerants ranged from pale green with diminutive leaf- or petallike structures to near white with relatively large petaloid structures. The 31 regenerated plants originated from 10 original tap root

selections. Regenerated plants were obtained from five each of the light- and dark-grown cultures (Table 1). All regenerated plants derived from an original root selection were identical with regard to male-sterile phenotype (Table 1). Male sterility in sexually propa-

Table 1. Number of sterile and fertile flowering plants from regenerants from cultures maintained under a 16-h photoperiod vs. continuous darkness.

\begin{tabular}{|c|c|c|c|c|}
\hline \multirow{3}{*}{$\begin{array}{l}\text { Original } \\
\text { plants }^{z}\end{array}$} & \multicolumn{4}{|c|}{ No. regenerants } \\
\hline & \multicolumn{2}{|c|}{ 16-h photoperiod } & \multicolumn{2}{|c|}{ Darkness } \\
\hline & Fertile & Sterile & Fertile & Sterile \\
\hline$\overline{\mathrm{L} 4}$ & 0 & 3 & & \\
\hline L5 & 0 & 6 & & \\
\hline L7 & 1 & 0 & & \\
\hline L8 & 2 & 0 & & \\
\hline L10 & 1 & 0 & & \\
\hline Total & 4 & 9 & & \\
\hline D1 & & & 0 & 1 \\
\hline D2 & & & 0 & 4 \\
\hline D3 & & & 0 & 4 \\
\hline D7 & & & 0 & 7 \\
\hline D9 & & & 2 & 0 \\
\hline Total & & & 2 & 16 \\
\hline
\end{tabular}

${ }^{2}$ Regenerated plants were derived from cultures that were from a root explant of a single plant; cultures in light or darkness (L and D, respectively) of the same numerical designation (e.g., L1 and D1) are from different original plants.

Table 2. Summary of the results of sterile carrot regenerant $\mathrm{x}$ maintainer and restorer crosses.

\begin{tabular}{|c|c|c|c|}
\hline \multirow{2}{*}{$\begin{array}{l}\text { Year of } \\
\text { progeny } \\
\text { test }\end{array}$} & \multirow[b]{2}{*}{ Description of $\operatorname{cross}^{\mathrm{z}, \mathrm{y}, \mathrm{x}, \mathrm{w}}$} & \multicolumn{2}{|c|}{$\begin{array}{c}\text { No. progeny } \\
\text { from individual cross }\end{array}$} \\
\hline & & Sterile & Fertile \\
\hline \multirow[t]{17}{*}{1990} & $\mathrm{SR} \times \mathrm{M}$ & 8 & 0 \\
\hline & $\mathrm{SR} \times \mathrm{M}$ & 2 & 0 \\
\hline & $\mathrm{SR} \times \mathrm{M}$ & 13 & 0 \\
\hline & $\mathrm{SR} \times \mathrm{M}$ & 15 & 0 \\
\hline & $\mathrm{SR} \times \mathrm{M}$ & 12 & 0 \\
\hline & $\mathrm{SR} \times \mathrm{M}$ & 6 & 0 \\
\hline & $\mathrm{SR} \times \mathrm{M}$ & 6 & 0 \\
\hline & $\mathrm{SR} \times \mathrm{M}$ & 9 & 0 \\
\hline & $\mathrm{SR} \times \mathrm{M}$ & 8 & 0 \\
\hline & $\mathrm{SR} \times \mathrm{R}$ & 2 & 2 \\
\hline & $\mathrm{SR} \times \mathrm{R}$ & 1 & 3 \\
\hline & $\mathrm{SR} \times \mathrm{R}$ & 3 & 2 \\
\hline & $\mathrm{SR} \times \mathrm{WR}$ & 9 & 1 \\
\hline & SR $\times W R$ & 3 & 0 \\
\hline & $\mathrm{SR} \times \mathrm{WR}$ & 0 & 2 \\
\hline & $\mathrm{SR} \times \mathrm{WR}$ & 1 & 1 \\
\hline & $\mathrm{SR} \times \mathrm{WR}$ & 3 & 0 \\
\hline \multirow[t]{17}{*}{1991} & $(\mathrm{SR} \times \mathrm{M}) \times \mathrm{M}$ & 1 & 0 \\
\hline & $(\mathrm{SR} \times \mathrm{M}) \times \mathrm{M}$ & 6 & $2^{v}$ \\
\hline & $(\mathrm{SR} \times \mathrm{M}) \times \mathrm{M}$ & 7 & $1^{\mathrm{v}}$ \\
\hline & $(\mathrm{SR} \times \mathrm{M}) \times \mathrm{M}$ & 8 & 0 \\
\hline & $(\mathrm{SR} \times \mathrm{M}) \times \mathrm{M}$ & 6 & 0 \\
\hline & $(\mathrm{SR} \times \mathrm{M}) \times \mathrm{M}$ & 7 & 0 \\
\hline & $(\mathrm{SR} \times \mathrm{M}) \times \mathrm{M}$ & 6 & 0 \\
\hline & $(\mathrm{SR} \times \mathrm{M}) \times \mathrm{M}$ & 10 & 0 \\
\hline & $(\mathrm{SR} \times \mathrm{M}) \times \mathrm{M}$ & 7 & 0 \\
\hline & $(\mathrm{SR} \times \mathrm{M}) \times \mathrm{M}$ & 8 & 0 \\
\hline & $(\mathrm{SR} \times \mathrm{M}) \times \mathrm{M}$ & 8 & $1^{\mathrm{v}}$ \\
\hline & $(\mathrm{SR} \times \mathrm{M}) \times \mathrm{M}$ & 15 & 0 \\
\hline & $(\mathrm{SR} \times \mathrm{M}) \times \mathrm{M}$ & 6 & 0 \\
\hline & $(\mathrm{SR} \times \mathrm{M}) \times \mathrm{R}$ & 2 & 2 \\
\hline & $(\mathrm{SR} \times \mathrm{M}) \times \mathrm{WR}$ & 4 & $3^{v}$ \\
\hline & $(\mathrm{SR} \times \mathrm{M}) \times \mathrm{WR}$ & 1 & $2^{v}$ \\
\hline & $(\mathrm{SR} \times \mathrm{M}) \times \mathrm{WR}$ & 1 & 0 \\
\hline \multirow[t]{4}{*}{1992} & {$[(\mathrm{SR} \times \mathrm{M}) \times \mathrm{M}] \times \mathrm{M}$} & 6 & 0 \\
\hline & {$[(\mathrm{SR} \times \mathrm{M}) \times \mathrm{M}] \times \mathrm{M}$} & 7 & 0 \\
\hline & {$[(\mathrm{SR} \times \mathrm{M}) \times \mathrm{M}] \times \mathrm{M}$} & 6 & 0 \\
\hline & {$[(\mathrm{SR} \times \mathrm{M}) \times \mathrm{M}] \times \mathrm{M}$} & 7 & 0 \\
\hline
\end{tabular}

${ }^{\mathrm{z}} \mathrm{SR}=$ sterile regenerant.

y4367M or 3640M provided by P.W. Simon and designated as maintainer of petaloid male sterility (M).

‘'Nangro'; designated as strong restorer of petaloid male sterility (R).

w'Slendero'; designated as weak restorer of petaloid male sterility (WR).

vartially fertile. gated 'Slendero' is extremely rare, $<1.0 \%$ (data not shown).

The results of three cycles of progeny tests of sterile regenerants and known petaloid maintainers and restorers are summarized in Table 2. Crosses of male-sterile regenerants with petaloid maintainers made in 1990 gave rise to completely sterile progeny. Progeny tests of sterile $x$ maintainer crosses conducted the following year resulted in three of 13 families segregating for partial restoration of fertility. Such partial restoration also occurred in sterile X DNAP 162 (weak restorer) crosses.

Sources of DNA extracts used for comparison of $m t D N A$ restriction patterns are summarized in Table 3. mtDNA digests with EcoRI, BamHI, HindIII, EcoRV, PvuII, BglII, and HaeIII proceeded to completion, giving welldefined DNA fragment patterns (Fig. 2). NotI did not digest any of the mtDNA samples. The spontaneous 'Slendero' volunteer sterile, all sterile regenerants, and the progeny of two fertile regenerants segregating for sterile and fertile phenotypes all had the same digestion patterns as the petaloid tester $(4367 \mathrm{~S})$ and the hybrid 'Chrisna' (data not shown). The digestion patterns for the sterile and fertile regenerants, as well as the petaloid CMS and maintainer lines, differed from the brown anther CMS line for all enzymes tested.

The fertile regenerant consistently exhibited a digestion pattern distinct from the original 'Slendero' population, nearly identical to that of the petaloid CMS maintainer line (4367M), and different from that of all other segregating fertile and sterile somaclones. The only difference between the fertile regenerant and $4367 \mathrm{M}$ was a single polymorphism identified in digests with the four-cutter HaeIII. HaeIII digests of the petaloid CMS maintainer line $4367 \mathrm{M}$ yielded a unique fragment not found in the fertile regenerant or any of the CMS regenerants.

The digestion patterns for the original 'Slendero' population were different from those of all other lines. 'Slendero' shared bands with the CMS and fertile regenerants but also had unique bands. Based on the number of distinguishing polymorphisms, 'Slendero' was more similar to fertile regenerant DW89-1213 than to the sterile regenerants.

\section{Discussion}

Our paper describes the phenomenon of recovering a high frequency of CMS plants in regenerants from tap-root-derived 'Slendero' carrot cultures. Because the nuclear genetic background of 'Slendero' with respect to petaloid CMS is that of "weak restorer" (sterile $\mathrm{x}$ 'Slendero' yields 20 fertile : 80 sterile progeny; unpublished results), sterile plants should be frequent if CMS is present. Therefore, it appears likely that the developmental process by which tap root cells proliferated in vitro was associated with specific, independent mutations, or selections thereof, that resulted in petaloid CMS. Likewise, it is unlikely that such variants already were present in the plants from which explants were obtained, unless, as 
suggested by Shirzadegan et al. (1989), cytoplasmic genomes consisted of heterogeneous fertile-sterile mixtures that "sorted out" during the cell culture process. Because all regenerated plants from distinct cultures were either all fertile or all sterile, it is likely that the mutational events or selection of previously existing mutants occurred early in the culture establishment phase or existed before this phase.

In most cases where CMS has been sub-

jected to rigorous molecular scrutiny, very strong circumstantial evidence has been obtained that supports the hypothesis that mtDNA structural rearrangements and corresponding altered gene expression are responsible for CMS (Leaver et al., 1989; Levings and Dewey, 1988). Reports specific to CMS in carrot have been consistent with this conclusion (Pingitore et al., 1989; Scheike et al., 1992). Also, partial reversion of petaloid CMS to fertility has been associated with mtDNA structural alterations

Table 3. Carrot lines used for comparisons of mtDNA restriction patterns.

\begin{tabular}{ll}
\hline \hline Line & \multicolumn{1}{c}{ Description } \\
\hline Slendero & Original seed lot of DNAP 162 that served as the source of explants \\
4367S & Petaloid cytoplasmic male sterility (CMS) tester provided by P.W. Simon \\
4367M & Petaloid CMS maintainer tester provided by P.W. Simon \\
Chrisna & A commercial hybrid cultivar bred and produced using petaloid CMS provided \\
& by Jay Schafer of the Alf Christianson Seed Co. \\
D488 & Brown anther CMS tester, provided by P.W. Simon \\
DG91459 & Volunteer petaloid male-sterile derivative from seed-propagated DNAP 162 \\
DW89-1213 & Fertile regenerant (R ) \\
DW89-1262.8951 & Sterile regenerant x 4367M \\
DW89-1263.8951 & Sterile regenerant x 4367M \\
DW89-1252.8972 & Sterile regenerant x 'Slendero' \\
DW89-1262.8972 & Sterile regenerant x 'Slendero' \\
DW89-1339 & Sterile regenerant x 'Slendero' \\
DW89-1360 & Sterile regenerant x 'Slendero'; sterile progeny selected and crossed with 4367M; \\
& Subsequent progeny segregating 1 fertile : 1 sterile \\
DW89-1370 & Sterile regenerant x 'Slendero'; sterile progeny selected and crossed with 4367M; \\
& subsequent progeny segregating 1 fertile : 5 sterile \\
\hline
\end{tabular}

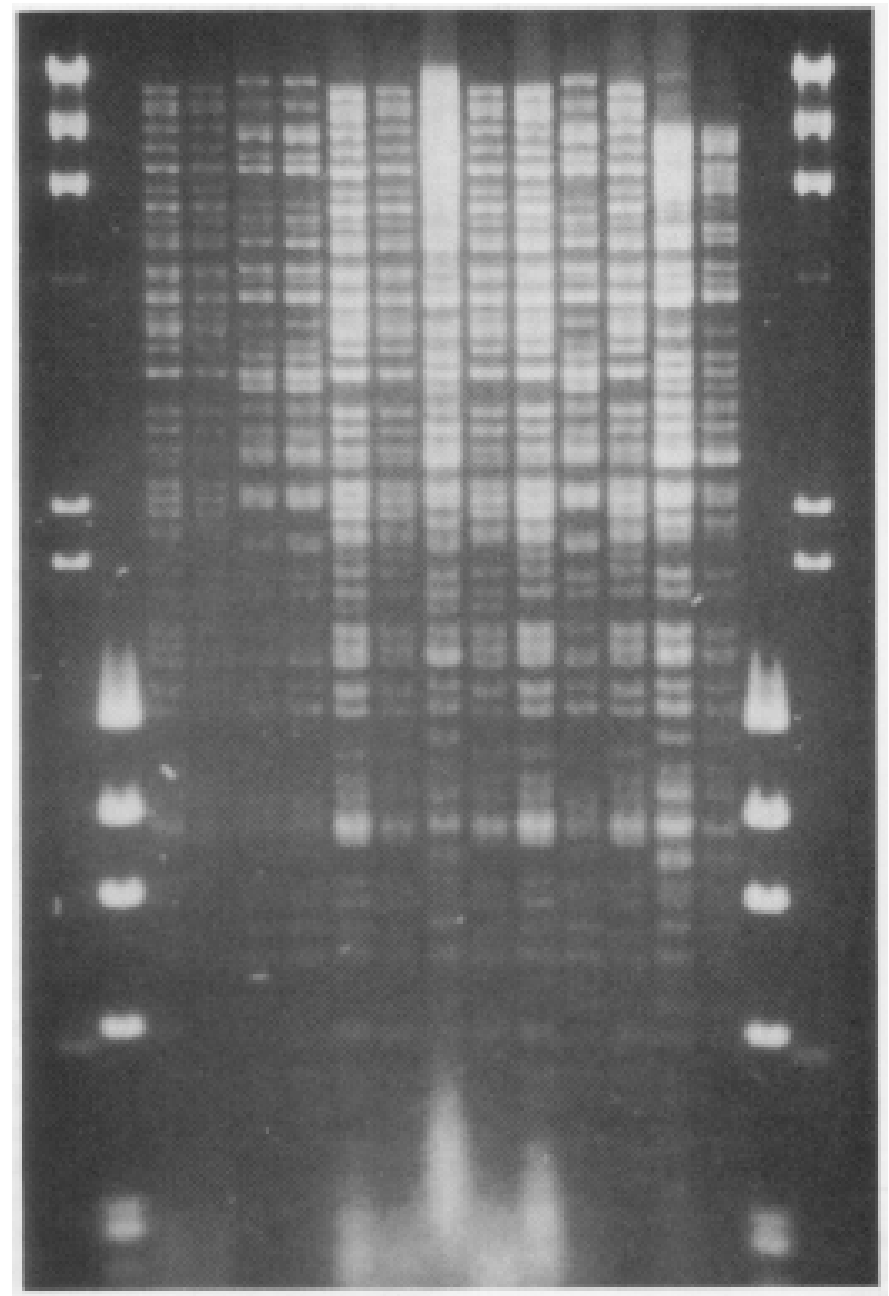

Fig. 2. EcoRI digests of mitochondrial DNAs from sterile and fertile regenerants and known genetic testers.
(Chahal and Wolyn, 1992). The CMS trait recovered from carrot cell cultures in this study exhibited characteristics identical to those of the "Cornell" petaloid male sterility first discovered by H.M. Munger and now in wide use for producing seed of hybrid carrot varieties (Peterson and Simon, 1986). Specifically, the maternally inherited component of the genetic determinants interacted consistently with established restorers and maintainers of petaloid male sterility. Also, restriction patterns of sterile regenerants were identical to those of petaloid CMS derived from the original Cornell selection.

Structural variability of mtDNA is associated with plant cell culture in maize (Zea mays L.) (Earle et al., 1987; Gengenbach et al., 1981; McNay et al., 1984). Reports also have appeared regarding the regeneration of fertile revertants from cultures derived from CMS plants (Earle et al., 1987; Gengenbach et al., 1981). In our study, two distinct mtDNA restriction pattern groups were detected among regenerants: that identical to petaloid CMS (plants sterile or segregating) and a new, distinct pattern (fertile), both of which were extensively altered from the restriction pattern of 'Slendero'. We conclude that cell cultures from tap root explants of the 'Slendero' carrot were associated either with extensive, identical mtDNA rearrangements or with the selectin of low-frequency, pre-existing heterogeneous petaloid CMS mtDNA variants. Although petaloid sterility is environmentally stable (data not shown), we observed some partial reversion to fertility following the second cycle of crosses to known petaloid maintainers. Possible explanations for this phenomenon include 1) petaloid CMS derived from cell cultures is inherently more unstable than that from sexually propagated populations, 2) revertants occurred in derivatives of regenerated plants, and 3) the maintainer population was contaminated with a low frequency of plants bearing restoration alleles.

Most rearranged mtDNA genomes were identical to that of the Cornell petaloid CMS, and corresponding plants exhibited some form of petaloid CMS. One fertile regenerant had a novel mtDNA structure nearly identical to that of the petaloid maintainer line $4367 \mathrm{M}$. Curiously, the floral morphology of the petaloid CMS plants was variable, ranging from pale green to more showy white types. We speculate that this was due to the interaction between the CMS mtDNA genotype with differing nuclear backgrounds.

'Slendero' carrot is a true Nantes type. To date, petaloid CMS has not been used in breeding Nantes hybrids due to the time and expense required in developing isogenic, sterile maintainer pairs (P. Simon, personal communication). Using cell culture to rapidly develop CMS breeding lines in a broad array of genetic backgrounds could greatly reduce the cost and time necessary to develop sterile maintainer pairs for breeding hybrid varieties. Similar experiments with contrasting carrot genotypes should be conducted to assess the general ability of this concept to be applied in hybrid carrot breeding. 


\section{Literature Cited}

Chahal, A. and D.J. Wolyn. 1992. Analysis of a fertile revertant from petaloid cytoplasm in male sterile carrot. Plant Physiol. 99:92.

Earle, E.D., V.E. Gracen, V.M. Best, L.A. Batts, and M.E. Smith. 1987. Fertile revertants from s-type male-sterile maize grown in vitro. Theor. Appl. Genet. 74:601-609.

Gengenbach, B.G., J.A. Connelly, D.R. Pring, and M.F.Conde. 1981. Mitochondrial DNA variation in maize plants regenerated during tissue culture selection. Theor. Appl. Genet. 59:161-167.

Hansche, P.E. and W.H. Gabelman. 1963. Digenic control of male sterility in carrots, Daucus carota L. Crop Sci. 3:383-386.

Kemble, R.J. 1987. A rapid, single leaf nucleic acid assay for determining the cytoplasmic organelle complement of rapeseed and related Brassica species. Theor. Appl. Genet. 73:364-370.

Leaver, C.J., P.G. Isaac, I.D. Small, J. Bailey-Serres, A.D. Liddell, and M.J. Hawkesford. 1988. Mitochondrial genome diversity and cytoplasmic male sterility in higher plants. Philosophical Trans. Royal Soc. London B 319:165-176.
Levings, C.S., III, and G.G. Brown. 1989. Molecular biology of plant mitochondria. Cell 56:171179

Lonsdale, D.M. 1989. The plant mitochondrial genome, p. 229-295. In: A. Marcus (ed.). The biochemistry of plants. vol. 15. Academic, New York.

McNay, J.W., P.S. Chourey, and D.R. Pring. 1984 Molecular analysis of genomic stability of mitochondrial DNA in tissue cultured cells of maize. Theor. Appl. Genet. 67:433-437.

Murashige, T. and F. Skoog. 1962. A revised medium for rapid growth and bioassay with tobacco tissue cultures. Physiol. Plant. 15:473497.

Peterson, C.E. and P.W. Simon. 1986. Carrot breeding, p. 321-356. In: M.J. Bassett (ed.). Breeding vegetable crops. AVI Publishing, Westport, Conn.

Pingitore, M., B. Matthews, and P.J. Bottino. 1989. Analysis of the mitochondrial genome of Daucus carota with male sterile and male fertile cytoplasm. J. Hered. 80:143-145.

Reynolds, J.F. 1986. Transfer of male sterility in carrots. Patent no. WO86/07379, World Intel- lectual Property Organization, Geneva, Switzerland.

Scheike, R., E. Gerold, A. Brennicke, M. MehringLemper, and G. Wricke. 1992. Unique patterns of mitochondrial genes, transcripts, and proteins in different male sterile cytoplasms of Daucus carota. Theor. Appl. Genet. 83:419-427.

Shirzadegan, M., M. Christey, E.D. Earle, and J.D. Palmer. 1989. Rearrangement, amplification, and assortment of mitochondrial DNA molecules in cultured cells of Brassica campestris. Theor. Appl. Genet. 77:17-25.

Tanno-Suenaga, L., H. Ickikawa, and J. Inamura 1988. Transfer of the cytoplasmic male sterility trait in Daucus carota L. by donor-recipient protoplast fusion. Theor. Appl. Genet. 76:855860.

Thompson, D.J. 1962. Studies on the inheritance of male-sterility in the carrot Daucus carota L. var. sativa. Proc. Amer. Soc. Hort. Sci. 78:332337.

Wilson, A.J. and P.S. Chourey. 1984. A rapid, inexpensive method for the isolation of restrictable mitochondrial DNA from various plant sources. Plant Cell Rpt. 3:237-239. 